self-examination of the breasts for signs of breast cancer.

There are two trends in the development of screening facilities - the use of simpler techniques for laboratory tests, and automation. A machine devised in Sweden works with discrete samples and includes a small computer, and can process some 500,000 samples a year with 20 analyses on each sample.

The usefulness of mass screening is illustrated in the current issue of Lancet, in which two general practitioners, a London borough health department, and a university department of surgery cooperated in a survey to detect cancer of the breast in London practice. The results of the survey are:

\begin{tabular}{lccc} 
Total number of women invited &.. & 1,721 \\
Number attended .. &.. &.. & 654 \\
Abnormality suspected &. &. & $72(11 \%)$ \\
Clinical confirmation &. &. & 23 \\
Not re-confirmed .. &. &. & 5 \\
\hline
\end{tabular}

Of the 18 confirmed cases, two refused further treatment, five had cancer of the breast and the other eleven had various benign lesions. (Lancet, i, 1419; 1968.)

\section{Schools Commission Recommissioned}

The Public Schools Commission has been equipped with eleven new members and a new chairman, Dr D. V. Donnison, who is professor of social administration at the London School of Economics. The commission began its inquiries in February 1966 under the chairmanship of Sir John Newsom. Its first report, which will discuss how the public schools should be integrated with the state system, is to be published on July 23 .

The report is not expected to contain any particularly radical proposals, despite the menaces once detected in its constitution and terms of reference. The public schools have apparently tamed the zeal of even their most hostile inquisitors, who in any case faced a somewhat intractable issue. The choices before them were to abolish the public schools altogether, to stipulate that the schools should open a percentage of their places to Government supported pupils, and to leave them as they are. Some public schools provide an excellent educational service, to those that can afford it, not least because of the high staff : student ratio they maintain. It would be a negative measure to abolish the schools entirely, yet there are severe problems in doing anything less. Local education authorities invited to support students at public schools have always been reluctant to meet the higher fees and in the past the places offered to them by various public schools have not fully been taken up.

The alternative to local authority support is that central government should finance a publie school education for selected pupils. But to send the best pupils to public schools would betoken a lack of confidence in the state system and provoke a predictably unsympathetic reaction from its teachers; whilo to select students for public schools on any grounds other than merit would raise cries of anguish from disappointed parents.

The problem about the public schools is that, given the chance, many people would prefer to enrol their children there rather than at state schools. To integrate the two systems would entail giving formal recognition to the public schools' greater popularity. The Public Schools Commission has apparently discovered no escape from this dilemma, and the objects of its inquiry are expected to continue much as before.

This is in many ways a pity, because the kind of segregation perpetuated by the public schools system is doubtless a handicap to its pupils and divisive to society at large. The people most eager to remedy this situation are probably the teachers and administrators at public schools, but as independent critics of the Government's educational policies they do not always see eye to eye with what are sometimes regarded as the doctrinaire approaches to the problem adopted by the Department of Education and Science.

The reconstituted commission is to consider its remaining terms of reference, which are to advise on the integration of day independent and direct grant grammar schools.

\section{Another A-Level}

ONE of the proposals for sixth-form experiment now filtering its way through to the joint working party of the Schools Council and the Standing Conference on University Entrance is a scheme for teaching mathematics and physics in combination, chiefly for the benefit of intending biologists but also in the hope that such a course will provide non-scientists with an easy (and rewarding) way of learning a little science. The initiative for this proposal has come from Mr David Tomes, head of the physics department at Wellington College. He has enlisted the help of Mr John Osborne, senior science master at Westminster School, and both of them have been encouraged by the friendly reception their proposals have received from other teachers and even from the Schools Council. Their next objective will be to interest half a dozen schools in teaching their course, ideally in the school year beginning in September 1969. To reach this goal, it will be necessary for them to persuade the examinations boards to provide a suitable examination and also the universities to accept an A-level in physies and mathematics combined as a suitable qualification for entry.

$\mathrm{Mr}$ Tomes is particularly anxious to win the interest of the medical schools; he points out that the course he is designing is one of the few ways in which intending medical students can come closely into contact with mathematics in the sixth form. At present, in Britain, intending medical students tend to follow courses in physics, chemistry and as much biology as they can stomach, with the result that they may finish up knowing nothing of calculus or probability. There are several reasons why a combination of physics and mathematics should seem preferable to the combination of physics and chemistry now being taught in some schools under the label of Nuffield physical science-for one thing, it should be a good deal easier to teach. The other side of that coin, however, is that the physical science course allows sixth-formers to postpone a decision about the kind of science they will eventually settle for at least until they have finished their examination. The combination of physics and mathematies will necessarily distinguish from the beginning between intending biologists and the rest.

In the long run, of course, the success of this A-level course, like that of the other variations on the traditional pattern of science education in British schools, 